\title{
Current Situation and Construction Strategy of Bird Habitats in River Wetland Parks in Cities of Sichuan Province
}

\author{
Chunyan Zhu' ${ }^{1}$ Yujia Zhang', Yuanyuan Zhang ${ }^{1}$, Yizhi Jiang ${ }^{1}$ \\ ${ }^{1}$ Sichuan Agricultural University, Chengdu, Sichuan Province, China
}

Keywords: urban wetlands along rivers; bird habitats; habitat construction

\begin{abstract}
Cities of Sichuan Province are rich in rivers and diverse landscape resources. Tidal-flat areas and wetlands along riverbanks are important habitats for birds. With the promotion of urbanization, however, the environmental conditions of these areas are destroyed in different degrees. Water pollution and ecological degradation pose a threat to the survival and reproduction of birds. Bird habitats in these wetlands need urgent protection, restoration and construction. This paper analyzes the present situation and problems of urban wetlands along rivers. Based on river theory, as well as intermediate disturbance hypothesis and edge effect theory, the paper puts forward the idea of constructing bird habitats in urban wetlands, and explores the construction strategy.
\end{abstract}

\section{Present Situation of Bird Habitats in River Wetland Parks in Cities of Sichuan}

Sichuan has a huge number of rivers and streams. Among the 1419 rivers, the drainage areas of 345 exceed 500 square kilometers; the drainage areas of 22 exceed 1000 square kilometers. Thus, Sichuan is also called "the province with numerous rivers, streams and lakes". Rivers pass through most of the cities in Sichuan province. Wetlands and landscape resources abound in banks of rivers; these wetlands are important habitats for birds.

With the promotion of urbanization, the environmental conditions of these areas are destroyed in different degrees. Many environment problems, such as water pollution and ecological degradation arise. Large area of shrubs, wetlands and tidal flats are reformed and replaced by artificial turf and hard banks. Birds are facing with great threat against their reproduction and survival since they are very sensitive to environmental changes.

In recent years, the pace of urban construction has slowed down; people have paid attention to ecological and environmental problems. The destruction of bird habitats is alleviated. Statistical data on bird resources of Sichuan Province shows that the number and species of birds are gradually increasing. [1] However, some birds are doomed to be extinct in Sichuan. Bird habitats in urban wetlands along rivers are still in urgent need of protection; the restoration of bird habitats is imminent.

\section{Research Status and Significance of Constructing Bird Habitats in River Wetland Parks}

Habitat refers to the environment in which animal lives. It is the sum of various ecological environmental factors related to the birth and growth of individual animals, as well as the distribution of animal populations and animal communities. The quality of habitat plays a significant role in the diversity and richness of bird resources. Urban wetlands along rivers are the boundary between water and land in cities. Water and land constitute the main parts of the environment. Wetlands are good places for travel and leisure, and excellent habitats for birds, since they can provide rich biological resources.

The process of urbanization has led to the transformation of junction areas between land and water. The hard, impervious embankment used for flood control has replaced the original natural wetlands, and blocked the exchange of energy and resources. The transformation leads to habitat loss for water birds, aggravated pollution of water body and ecosystem degradation. As the habitats of birds are seriously damaged, the species and quantity of birds fell sharply; some rare birds are extinct. 
The survival of birds can reflect the quality of urban landscape. Results show that, with the promotion of urbanization, the richness and species diversity of bird community decrease. [2] Tidal flats and wetlands along rivers and urban green space provide birds with living conditions; they have an important influence on the survival and reproduction of birds in cities. The structure and function of bird communities closely are related to their habitats and can reflect the quality of local ecological environment. [3] Therefore, it is important to analyze the relationship between the survival of birds and their habitats, namely green space and wetlands along rivers in cities, and to study habitat construction methods and influencing factors. The research can provide important scientific basis for the survival and protection of birds, and for the construction of urban ecological environment.

\section{Current Situation and Existing Problems of River Wetland Parks}

In the waterfront space of cities, squares are usually built along with green space to meets citizens' leisure needs and improve urban environmental and ecological conditions; in squares, human activities are too much. [4] Although squares can promote the interaction between people, most of them do not have landscape environments that are conducive to the survival of birds. They inhibit bird activities and are not conducive to the protection of birds. Meanwhile, the water quality of some urban rivers is poor; there are fewer birds live by the riverside. Most riverbanks are rectangular or trapezoid shaped hard refutation. With poor permeability, these riverbanks reduce the biological diversity on both sides of the river, and block the circulation of groundwater water. Meanwhile, river structures destroy the continuity of rivers and obstruct the migration and reproduction of birds.

\subsection{Improper sewage treatment}

The improper sewage treatment leads to the deterioration of water quality and destroys the river ecosystem. The pollution of water causes the gradual deterioration of ecological environment of rivers. The increasing pollutants in river courses and the pollution of water body lead to the reduction of aquatic organism. Birds' food sources are reduced to some extent; plants grown on riverbanks are also affected. The whole ecosystem of river is severely damaged.

\subsection{Cut-off watercourses}

In many cities, the winding natural riverbanks are cut and straightened. The cut-off watercourses destroy the original hydro geological and geomorphology conditions, reduce the permeability of riverbanks, and deprive their water regulation functions. Birds' choices of habitats are limited. With the reducing of water surface, it is difficult to adjust urban microclimate and construct ecological landscapes. [5] Some river structures block the migration of fish, and hinder the process of water circulation, resulting in the loss of aquatic habitat and the destruction of ecological community structure.

\subsection{Hard river revetment}

The hard river revetment plays a positive role in ensuring the safety of the city from the perspectives of maintaining the stability of bank slope, preventing soil erosion and controlling flood. However, it has bad effects on landscape and ecology environment in varying degrees. The river revetment separates water from soil, and damages the energy and material circulation systems between water, land and aquatic organisms. River wetland system cannot be built. It also aggravates the degree of water pollution, weaken the self-purification capacity of rivers, reduce variety of life and hindered the construction of bird habitat.

\subsection{Inadequate green space}

The small area and limited quantity of green space along riverside indicate that, when planning and building water ways, relevant decision-making departments did not pay enough attention to the construction of ecological system and landscape. Waterfront area is the corridor in which human ecosystem intersects with plant and animal ecosystems of littoral zone. The central city is a typical "edge effect" area. Therefore, the reasonable area of green space along rivers plays an important role 
in the construction and effect of ecosystem and bird habitat.

\subsection{Simple plant configuration}

Plant configuration is simple and lacks of aquatic plants. According to survey reports, in the downtown area of Chengdu, plant configuration is made along most of the river channels. But there are two problems. First, the plant configuration is simple; the levels are poor with few plant species. Second, most spaces do not use aquatic plants, resulting in the poor construction of ecosystem and inadequate self-purification capacity.

\section{Theories and Strategies on Bird Habitat Construction in River Wetland Parks}

\subsection{Theories about habitat construction in river wetlands parks}

Theory on River. The theory can be divided into two cases: continuum and non-continuum. It holds that the function and structure of a river will change with the increase of width or length of the river. For example, in near shore or source of the river, the biodiversity is generally high; in the middle or middle reaches of the river, the biodiversity is the highest because of the high habitat heterogeneity; in the lower reaches of the river, the biodiversity is the lowest due to the lack of changes in habitat. When restoring wetland ecosystem, the location of wetlands should be considered; wetland organisms should be restored.

Intermediate Disturbance Hypothesis and Edge Effect Theory. Wetlands are located at the edge of water and land; water level is common. So wetlands have obvious intermediate disturbance and edge effect. The Intermediate Disturbance Hypothesis is proposed by Joseph H. Connell, who believes that in intermediate disturbance place, the species richness is highest. Difficulty of this theory lies in how to determine the duration, frequency and intensity of disturbance. The Edge Effect Theory holds that due to the high heterogeneity, the species diversity is high in the area where two habitats overlap. Wetlands are located at the intersectional parts of land and water. In the biogeochemical cycle, wetland habitats play multiple roles: source, reservoir and transporter. They provide suitable conditions for all kinds of organisms, and have higher productivity compared with land and water.

\subsection{Strategies on the construction of bird habitats in river wetland parks}

Construction of wetlands and rivers. The construction of wetlands and rivers helps to realize the coexistence of human and birds. Built along the Banks of the river road, road and across a certain width between the bird island near the river. Plank roads are built along riverbanks; waterways with certain width are used to separate plank roads and bird islands nearby. Human areas and bird islands are separated by rivers. Citizens can watch birds, but birds are not affected by them.

Construction of three-dimensional green space. The species and quantity of birds grow with the increasing of the area of three-dimensional green space and complexity of its structure. Different birds have different demands for habitat. In the process of habitat construction, the depth and space of wetlands, as well as the height and species of nesting trees should be different. Therefore, the variety and abundance of plants should be improved in green spaces to enhance the integration, and build organic relationship between different habitats. It can also increase the diversity of birds.

Construction of natural revetment. In cities, most of the river banks are artificial linear and regular hard banks, which seriously destroy the natural structure and appearance of rivers. With obvious artificial landscape traces, there are few beaches and wetlands left. When choosing their habitats, birds and parts of wild animals are sensitive to the environment. They are not willing to choose areas with obvious artificial traces. Thus, the living spaces of birds are further compressed. Natural river revetment plays an important role in the construction of bird habitats. In order to construct bird habitats, it is important for us to demolish hard river banks and restore the natural ones.

Diversity and richness of plant community. We should pay attention to the diversity and richness of plant communities when constructing bird habitat in tidal flat wetlands along the rivers. The plant community is a key factor which affects birds' habitat selection. Different species of birds have different niche. Through diversifying plant species and vegetation community configuration, birds 
can be attracted and protected effectively.

In the course of river basin planning, construction and renovation, we should pay attention to the protection and reconstruction of aquatic plants like reeds and calamus, as well as secondary vegetation along the coast. "Permeable" ecological banks should be built to increase the diversity of river ecosystem, and provide food sources as well as habitats for birds. Green spaces should be built along rivers and traffic systems, so as to construct a green ecological corridor and provide more habitats for birds. The adaptability of birds can be improved. In this way, tidal flat wetlands on both sides of rivers could be constructed as bird habitats.

\section{Conclusion}

The core of constructing bird habitats in urban river wetlands is to use the favorable basis conditions and build urban river ecosystem, trying to make the urban river wetlands lively and vigorous. With good water quality, reasonable plant configuration and rich biological diversity, birds will be attracted to these areas. In cities, rivers and environment are disturbed by human activities; it is difficult to adopt the protection methods of natural habitats. But through reasonable ecological design, good habitat restoration and effective pollution control, it is possible to restore the ecological function of river wetlands and meet the requirements of bird habitats.

\section{References}

[1] Y. Xu, J.H. Ran, B.S. Yue, The latest statistics on bird species in Sichuan province, J. Sichuan Journal of Zoology. 27 (2008).

[2] S.H. Chen, P. Ding, G.M. Zheng, Y. Zhuge, Research prospect on urban bird community ecology, J. Chinese Journal of Zoology. 21 (2000).

[3] W.W. Lu, Studies on the Influence of Urbanization on Avian Community and Bird's Adaptation, East China Normal University, 2007.

[4] C.H. Zhang, Y.B. Guo, Dynamic monitoring and analysis of wetlands in Chengdu Plain, J. Journal of Anhui Agricultural Sciences. 45 (2017).

[5] G.L. Meng, The Construction Situation, Problems and Countermeasures of the River Landscape in Chengdu Downtown, Sichuan Agricultural University, 2012. 